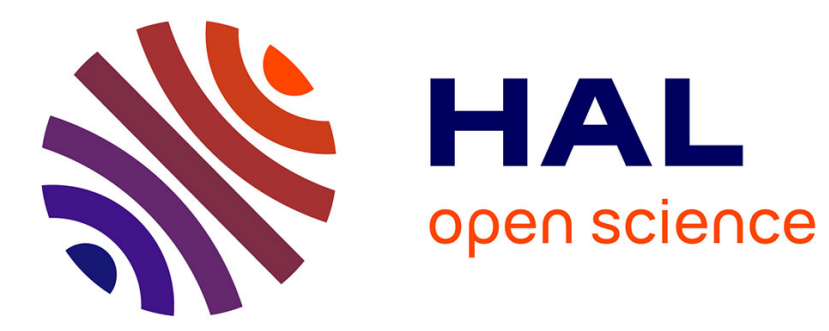

\title{
The effects of explosive-driven shocks on the natural remanent magnetization and the magnetic properties of rocks
}

\author{
J. Gattacceca, A. Lamali, P. Rochette, M. Boustie, L. Berthe
}

\section{To cite this version:}

J. Gattacceca, A. Lamali, P. Rochette, M. Boustie, L. Berthe. The effects of explosive-driven shocks on the natural remanent magnetization and the magnetic properties of rocks. Physics of the Earth and Planetary Interiors, 2007, 162 (1-2), pp.85-98. 10.1016/j.pepi.2007.03.006 . hal-00532102

\section{HAL Id: hal-00532102 \\ https://hal.science/hal-00532102}

Submitted on 4 Nov 2010

HAL is a multi-disciplinary open access archive for the deposit and dissemination of scientific research documents, whether they are published or not. The documents may come from teaching and research institutions in France or abroad, or from public or private research centers.
L'archive ouverte pluridisciplinaire HAL, est destinée au dépôt et à la diffusion de documents scientifiques de niveau recherche, publiés ou non, émanant des établissements d'enseignement et de recherche français ou étrangers, des laboratoires publics ou privés. 


\section{Accepted Manuscript}

Title: The effects of explosive-driven shocks on the natural remanent magnetization and the magnetic properties of rocks

Authors: J. Gattacceca, A. Lamali, P. Rochette, M. Boustie, L. Berthe

PII:

DOI:

Reference:

To appear in:

Received date:

Revised date:

Accepted date:
S0031-9201(07)00058-1

doi:10.1016/j.pepi.2007.03.006

PEPI 4803

Physics of the Earth and Planetary Interiors

20-10-2006

16-3-2007

21-3-2007

Please cite this article as: Gattacceca, J., Lamali, A., Rochette, P., Boustie, M., Berthe, L., The effects of explosive-driven shocks on the natural remanent magnetization and the magnetic properties of rocks, Physics of the Earth and Planetary Interiors (2007), doi:10.1016/j.pepi.2007.03.006

This is a PDF file of an unedited manuscript that has been accepted for publication. As a service to our customers we are providing this early version of the manuscript. The manuscript will undergo copyediting, typesetting, and review of the resulting proof before it is published in its final form. Please note that during the production process errors may be discovered which could affect the content, and all legal disclaimers that apply to the journal pertain. 
The effects of explosive-driven shocks on the natural remanent magnetization and the magnetic properties of rocks

J. Gattacceca ${ }^{*}$, A. Lamali ${ }^{2}$, P. Rochette ${ }^{1}$, M. Boustie ${ }^{3}$, L. Berthe ${ }^{4}$

${ }^{1}$ CEREGE (CNRS/Univ ersité Paul Cézanne), BP 80, 13545 Aix-en-Provence Cedex 4, France

${ }^{2}$ CRAAG, BP 63 Bouzaréah, 16340 Alger, Algeria

${ }^{3}$ LCD (CNRS/ENSMA), BP 40109, 8696 Futuroscope Cedex, France

${ }^{4}$ LALP (CNRS), 94114 Arcueil cedex, France

* corresponding author 
1

\section{2}

3

4

5

6

7

\section{Introduction}

The effects of shock waves on the natural remanent magnetization (NRM) and the intrinsic magnetic properties of geological materials remain poorly known. Still, hypervelocity impact phenomena are of primary importance in the evolution of many extraterrestrial bodies and of

Earth. Hence the magnetic anomalies associated with impact basins on Mars (Hood et al., 2003), the Moon (Halekas et al., 2003) or on Earth (Pilkington and Grieve, 1992) cannot be interpreted with certainty. Also, shock-induced changes of rock magnetic properties should be taken into account when studying the magnetic signature of terrestrial impact structures.

Since the 1970 's, efforts have been devoted to the experimental study of remagnetization of rocks upon impact, whereas little has been done about the shock-induced modifications of their intrinsic magnetic properties. Different techniques have been used to generate shock waves in a variety of geological materials: air guns accelerating aluminum or copper projectiles (Hornemann et al., 1975; Pohl et al., 1975; Martelli and Newton, 1977; Cisowski and Fuller, 1978; Srnka et al., 1979; Dickinson and Wasilewski, 2000), exp losives (Hargraves and Perkins, 1969; Pesonen et al., 1997), free falling mass (Kletetschka et al., 2004). Common limitations are the difficulty in calibrating the pressure in the shocked sample and the recovery of intact samples due to brecciation of the target. On the other hand modern mechanical impact experiments using gas guns can recover intact samples with good pressure calibration (e.g. Louzada et al., in press). Recently, the use of laser shocks allowed a good estimate of the demagnetization of saturation isothermal remanent magnetization up to $5 \mathrm{GPa}$ (Gattacceca et al., 2006), but the pressure gradient was limited to a few millimeters inside the sample, making it impossible to study the changes in intrinsic magnetic properties. Despite these numerous experiments, the effects of shock waves on magnetization and magnetic properties are not clearly understood in particular because of the numerous parameters that may have an influence: shock intensity and duration, ambient field, magnetic mineralogy, rheology, magnetization existing prior to shock, and temperature.

In this paper, we present new experiments in which different geological materials were impacted using a high-order explosive (penthrite). The shock wave was modelled numerically and we studied the effects of shock on the NRM and on the intrinsic magnetic properties of the rocks.

\section{Material and methods}

3 Four different lithologies were studied: a Quaternary alkaline basalt (from the Bas-Vivarais 3 area, France, described in Rochette et al. (1993), a Tertiary quartzitic microdiorite 
("esterellite", from the Estérel range near the southeastern coast of France), a Permian rhyolitic pyroclastic rock from the same area (Vlag et al., 1997), and a PrecambrianOrdovician pyrrhotite-rich metamorphic schist from Wilson Terrane (Northern Victoria Land, Antarctica). This choice was guided by the differences in magnetic mineralogy and magnetic properties among these four lithologies.

The shock wave was driven into the samples using a high-order explosive (penthrite, PETN). The shocked samples were large blocks in the range $10-20 \mathrm{~kg}$. A flat surface was cut using a circular saw. The sample was then placed in a large $\left(0.3 \mathrm{~m}^{3}\right)$ plastic container half-filled with gravel. A penthrite detonator $(0.2 \mathrm{~g}$ of penthrite contained in an aluminium cylinder of external diameter $7.3 \mathrm{~mm}$ and thickness $0.5 \mathrm{~mm}$ ) was fixed in direct contact with the flat, locally polished surface of the sample. The container was then filled with gravel. The penthrite was detonated remotely using a non-electric detonating wire. The outdoor experimental setting contained no metallic parts except the aluminium cylinder containing the penthrite, and no electromagnetic signal is expected during the detonation. Therefore we did not use any system of magnetic field control and assume that the magnetic field seen by the sample is the local geomagnetic field $\left(\mathrm{I}=59^{\circ}, 46 \mu \mathrm{T}\right)$. Each sample was oriented so that its original NRM made an angle of about $90^{\circ}$ with the local field. After recovery of the shocked samples, we drilled an oriented core $(\varnothing 2.5 \mathrm{~cm})$ perpendicular to the flat surface and centred on the impact. This core was in turn cut in 10 oriented $4 \times 4 \times 3 \mathrm{~mm}^{3}$ parallelepipeds with a wire saw (Fig. 1). Note that the upper few millimetres have been lost during the explosion for the basalt $(3 \mathrm{~mm})$ and the rhyolite $(8 \mathrm{~mm})$. In the following, the sample numbers correspond to the depth (in $\mathrm{mm}$ ) of the centre of the $3 \mathrm{~mm}$-high parallelepipeds from the original surface. All magnetic analyses were performed at CEREGE (Aix-en-Provence, France). The magnetization measurements were performed with a $2 \mathrm{G}$ Enterprises DC SQUID magnetometer and data processed with Paleomac software (Cogné, 2003). Magnetic susceptibility measurements and thermomagnetic analyses were performed with an Agico KLY2-CS2 apparatus. Hysteresis loops were studied with a Princeton Micromag VSM apparatus.

\section{Shock modelling}

In order to estimate the stress field induced in the samples by the explosions, a numerical simulation of the experiments was performed. For this purpose, the Radioss code [www.mecalog-group.fr] has been used in a 2D axisymmetric configuration. The explosive PETN has been modelled by a Johnson Wilkins Lee law (Wilkins, 1999): 


$$
P=A\left(1-\frac{\omega}{R_{1} V}\right) \exp \left(-R_{1} V\right)+B\left(1-\frac{\omega}{R_{2} V}\right) \exp \left(-R_{2} V\right)+\frac{\omega E}{V}
$$

70

71

72

where $\mathrm{P}$ is the pressure, $\mathrm{A}, \mathrm{B}, \mathrm{R} 1$ and $\mathrm{R} 2$ are empirical parameters, $\omega$ is the Gruneisen coefficient, $\mathrm{E}$ is the internal energy and $\mathrm{V}$ is the relative volume.

The modelled target material is a basalt described by an elasto-plastic constitutive law coupled to the Mie-Grüneisen equation of state with reference to the Hugoniot through a linear relationship between shock speed $D$ and particle velocity $u$ : $D=C_{o}+s . u$., where $C_{0}$ is the sound speed and $s$ is an empirical parameter. All the parameters used in the simulation are listed in table 1. In the model, the diameter of the basalt has been taken large enough $(6 \mathrm{~cm})$ to avoid lateral reverberations on the free surface during the duration of observation of the phenomena (first pass of the shock).

The modelled evolution of stress versus time at various depths is given in Fig. 2. The shock applied by the explosion has an almost triangular shape, with a peak pressure of $30 \mathrm{GPa}$ and a duration of about $1 \mu \mathrm{s}$. The peak pressure decays to $5 \mathrm{GPa}$ at only $20 \mathrm{~mm}$. At depth sreater than $5 \mathrm{~mm}$, following the compression the material is submitted to a tensile stress, due to the lateral release initiated at the rim of the explosive charge, which generates expansion when crossing behind the main shock.

According to the assumptions made for this simulation (homogeneous, isotropic and non porous rock), and the variability of the intrinsic petrophysical parameters among the four different samples (for instance bulk density is $2270 \mathrm{~kg} \cdot \mathrm{m}^{-3}$ for the rhyolite, $2700 \mathrm{~kg} \cdot \mathrm{m}^{-3}$ for the microdiorite and the schist, and $3000 \mathrm{~kg} \cdot \mathrm{m}^{-3}$ for the basalt), we provide here only an estimate of the stress field into the samples. Based on this estimate, the depth scale for each shocked sample can be converted to a peak pressure scale (Fig. 3).

\section{Thermal modelling}

Because of the generation of the shock by a high explosive, an important heat flux is transferred to the target. The temperature profile applied to the target by this explosion has been calculated using the thermomechanical code Carte (Auroux and Deleignies, 2003) from the Commissariat à l'Energie Atomique (CEA, France). A maximum temperature of about $4500^{\circ} \mathrm{C}$ is applied during about $1 \mu \mathrm{s}$. A simulation of the dissipation of this heat into the target has been performed using a heat conduction simulation with FEMLAB 3.1 code (from COMSOL company). Physical properties introduced in the code are given in Table 1 . The temperature profile with depth is given in figure 4 and shows that the zone affected by a significant heating (temperature $>50{ }^{\circ} \mathrm{C}$ ) is restricted to the first upper micrometers. As a 
102 consequence, no thermal effect is expected at all on the magnetization and the magnetic

103 properties of the studied samples.

104 On the other hand, the shock wave itself is accompanied by a transient increase of 105 temperature. For pressure below the elastic limit of the rock ( $5 \mathrm{GPa}$ for a basalt), this 106 increase is negligible $\left(\sim 10^{\circ} \mathrm{C}\right)$. For pressure greater than the elastic limit, the increase in 107 temperature can be estimated to about $50^{\circ} \mathrm{C}$ at $10 \mathrm{GPa}$ and $100^{\circ} \mathrm{C}$ at $20 \mathrm{GPa}$ (e.g. Stöffler et 108 al., 1991 and references therein).

109

\section{Pre-shock magnetization and magnetic properties of the studied materials}

111 Thermomagnetic curves (Fig. 5) allow the determination of the main magnetic carrier in 112 the samples. The basalt has a main Curie temperature $\left(\mathrm{T}_{\mathrm{c}}\right)$ of $50{ }^{\circ} \mathrm{C}$ indicating Ti-rich 113 titanomagnetite of composition $\mathrm{Fe}_{0.25} \mathrm{Ti}_{0.75} \mathrm{O}_{4}$ (Dunlop and Özdemir, 1997). A second, less

114 substituted titanomagnetite population is evidenced by the blocking temperature spectrum of 115 thermoremanence that extends up to $350^{\circ} \mathrm{C}$ interval (Fig. 5). The microdiorite has $\mathrm{T}_{\mathrm{c}}=575^{\circ} \mathrm{C}$ 116 indicating almost pure magnetite. This is confirmed by the observation of a Verwey transition 117 at $114^{\circ} \mathrm{K}$. The rhyolite has $\mathrm{T}_{\mathrm{c}}=650^{\circ} \mathrm{C}$ indicating titanohematite. The thermomagnetic curve 118 for the schist shows the $\gamma$ transition (antiferromagnetic to ferrimagnetic) of hexagonal 119 pyrrhotite at $220^{\circ} \mathrm{C}, \mathrm{T}_{\mathrm{c}}=280^{\circ} \mathrm{C}$ of hexagonal pyrrhotite and $\mathrm{T}_{\mathrm{c}}=320^{\circ} \mathrm{C}$ of monoclinic 120 pyrrhotite. Hysteresis loops are in agreement with these interpretations (Fig. 6). For the 121 rhyolite, the wasp-waisted hysteresis loop evidences the existence of a minor amount of spinel 122 (titanomagnetite or titanomagh emite) in addition to titanohematite.

123 In view of the pressure profile in the samples $(\S 3)$ and the temperature increase associated 124 to the shock wave $(\S 4)$, no thermal effect is expected on the remanent magnetization or the 125 magnetic mineralogy of the studied rocks. Only for the basalt that has the lowest blocking 126 temperatures, a partial TRM acquisition (about 5-10\% of the total TRM, see Fig. 5) is 127 possible up to a distance of $10 \mathrm{~mm}$ away from the point of explosion, the temperature increase 128 at this distance being $\sim 50^{\circ} \mathrm{C}$.

129 To study the natural variability of magnetic properties within the studied rocks, we drilled 130 a $\varnothing 2.5 \mathrm{~cm}$ core parallel to the direction of the impact and more than $10 \mathrm{~cm}$ away from the 131 impact point. This core was cut in smaller samples whose hysteresis properties ( $\mathrm{B}_{\mathrm{c}}$ : 132 coercivity, $B_{c r}$ : coercivity of remanence, $M_{s}$ : saturation magnetization, $M_{r s}$ : remanente 133 magnetization at saturation), magnetic susceptibility, anisotropy of magnetic susceptibility 134 (AMS) and NRM were measured. The results show no significant variation of the NRM 135 intensity and magnetic properties with depth or mass of the sample. The only exception is a 
$50 \%$ increase of magnetic susceptibility in the upper $5 \mathrm{~mm}$ of the rhyolite sample. The basalt, the microdiorite and the rhyolite are magnetically homogeneous at the sampling scale $(\sim 200$ $\mathrm{mg}$ ). The schist is heterogeneous at scale $<1 \mathrm{~g}$ : although the magnetic carriers have identical hysteresis properties their concentration varies (and hence the magnetic susceptiblity and NRM) due to aggregation of pyrrhotite grains. The pre-shock magnetic properties are given in Table 2. In summary, we studied fours samples with the following dominant magnetic mineralogy: multidomain magnetite (microdiorite), pseudo-monodomain Ti-rich titanomagnetite (basalt), pseudomonodomain monoclinic pyrrhotite (schist) and monodomain titanohematite (rhyolite). The direction of the NRM of each sample was measured on an oriented fragment before the shock. The direction and intensity of the principal axis of magnetic susceptibility (noted $\mathrm{K} 1$ and $\mathrm{K} 3$ for the maximum and minimum axes, respectively) were evaluated on the same samples.

\section{Magnetic properties of shocked materials}

After measurement of the NRM (see next section), hysteresis parameters of shocked samples were measured (Fig. 6). The plots of the hysteresis properties versus the distance to the impact point show that for the basalt, the microdiorite and the schist, the coercivity and the remanent magnetization at saturation increase close to the impact (Fig. 7). The effect, already observed by Pesonen et al. (1997) is stronger for the microdiorite sample, with a fivefold increase of both parameters. In all three cases, the intrinsic magnetic properties of all samples are clearly modified by the shock wave. Various causes could explain the modifications of magnetic properties: change in magnetic grain size, wall displacement in the magnetic grains, shock-induced defects. We observed that the shock-induced changes in hysteresis properties are not removed by stepwise heating up to $580^{\circ} \mathrm{C}$. Therefore, these modifications are not attributable to stress whose effects would be annealed at rather low temperature (e.g. Van Velzen, 1992). Similarly, application of a strong field (up to 3 T) does not reset the original magnetic properties. Therefore, wall displacements cannot be the cause of the hysteresis modification. The only plausible explanation is a permanent modifications of the crystalline structure of the magnetite grains, namely microfractures, lattice defects or dislocations.

The bulk magnetic susceptibility and the AMS (except for the rhyolite and the schist) were measured after the shock. A slight decrease of magnetic susceptibility is observed for heavily shocked (titano-)magnetite-bearing samples (Fig. 8), as already evidenced in previous works (e.g. Hargraves and Perkins, 1969). 
It is noteworthy that for the basalt (with a pre-shock minimum susceptibility axis $\mathrm{K} 3$ that is about $30^{\circ}$ away from the direction of impact), the heavily shocked samples have a higher AMS degree (Fig. 9a) and their K3 axis is parallel to the direction of impact (Fig. 9b). For the microdiorite (with a pre-shock K3 axis that is perpendicular to the direction of impact), away from the impact point the $\mathrm{K} 3$ axes rotate from a direction parallel to the impact towards the pre-impact direction (Fig. 9b). The intensity of the AMS for the microdiorite does not decay away from the impact point as regularly as for the basalt, probably because we observe the progressive superimposition of two different fabrics: the original one and the impact-induced one. These observations show that the impact modified the existing magnetic fabric in the first $\mathrm{cm}$ (peak pressure $>10 \mathrm{GPa}$ ) of the shocked basalt and microdiorite sample despite the absence of visible macroscopic brecciation. The physical phenomena responsible for the shock-induced magnetic anisotropy may be small-scale fracturing and deformation of magnetite grains. It is unlikely that domain walls displacement by the shock wave is responsible for even a small fraction of the shock-induced magnetic anisotropy. Indeed, the magnetic anisotropy remains unchanged after application of high magnetic fields $(3 \mathrm{~T})$ that would reset any domain wall displacement.

\section{Magnetization of shocked materials}

\section{$188 \quad$ 7.1. Demagnetization data}

The NRM of all oriented sub-samples was measured and stepwise demagnetized with alternating field (AF) up to $140 \mathrm{mT}$ (Fig. 10). We also provide demagnetization data for unshocked samples.

Unshocked basalt samples possess a single component of magnetization that is interpreted as the original TRM. All shocked basalt samples posses a high coercivity component with a direction close to the magnetization of the unshocked sample, that represents what is left from the original TRM. The $\sim 20^{\circ}$ discrepancy between the pre- and post-shock high coercivity directions is easily explained by summing the orientation uncertainties when drilling the preand post-shock cores and when cutting and orienting the small parallelepipeds out of the postshock core. All shocked samples, even located at $3 \mathrm{~cm}$ from the impact (with an estimated peak pressure of $2 \mathrm{GPa}$ ), have acquired a second ary component that is completely erased at 5 $\mathrm{mT}$. This component of magnetization may be attributed to the shock or to the sawing process. Basalt samples located close to the impact $(<1 \mathrm{~cm}$, estimated peak pressure $202>10 \mathrm{GPa}$ ) possess a more stable secondary component isolated below $10 \mathrm{mT}$. This component may be interpreted as a shock remanent magnetization (SRM) acquired in the 
204

205

206

207

208

209

210

211

212

213

214

215

216

217

218

219

220

221

222

223

224

225

226

227

228

229

230

231

232

233

234

235

236

237

ambient magnetic field present during the explosion. However a thermoremanent origin cannot be excluded for this low-coercivity component in view of the low blocking temperatures of the basalt (see §4). Although poorly defined, the low coercivity directions are not closely related to the ambient field at the time of impact (Fig. 11). They lie within the plane defined by the pre-shock NRM and the ambient field.

For the microdiorite, the unshocked sample possesses two components of magnetization: a low coercivity component, isolated below $6 \mathrm{mT}$, and a high coercivity component that is not fully demagnetized at $150 \mathrm{mT}$. This latter component is interpreted as the original TRM. Despite the low bulk coercivity of the micriodiorite $(\mathrm{Bc}=2 \mathrm{mT})$, its natural TRM is carried by a high-coercivity fraction. The shocked samples still possess most of the original TRM. The shocked samples located close to the impact $(<1.5 \mathrm{~cm}$, peak pressure $>6 \mathrm{GPa})$ possess a secondary component isolated below $30 \mathrm{mT}$ and is interpreted as a SRM. The SRM directions are scattered.

For the rhyolite, the unshocked sample possesses a single component of magnetization carried by hematite. It is not clear if this original magnetization is a TRM or a chemical remanent magnetization (see discussion in e.g. Vlag et al., 1997). All shocked samples possess a high-coercivity component of similar direction than the origin al magnetization. The shocked samples closest to the impact point $(<1 \mathrm{~cm}$, peak pressure $>10 \mathrm{GPa})$ also possess a low-coercivity component (SRM) iso lated below $\sim 30 \mathrm{mT}$. The SRM directions are scattered.

The pyrrhotite-bearing schist did not provide stable directions of NRM when demagnetized by alternating field (Fig. 10). Therefore we will not discuss the possible remagnetization in the shocked schist.

\subsection{Remagnetization and demagnetization by shock}

In our experiments, since the directions of the original TRM and the SRM are different we cannot simply compare the intensities of the pre- and post-shock NRM. For the basalt for instance, the intensity of the total post-shock NRM is much lower than the sum of the intensities of the two components of magnetization (e.g. sample B5 of Fig. 10). In figure 12, we plot the scalar sum of the intensities of the stepwise-demagnetized magnetization vectors for basalt and microdiorite samples. The intensities are normalized to the saturation magnetization of each sample to take into account the natural variability in ferromagnetic mineral concentration. After the shock, the sum of the intensities of the different components of magnetization is weaker than before the shock for the basalt, but higher for the microdiorite. The basalt is globally demagnetized whereas the microdiorite is globally 
238

239

240

241

242

243

244

245

246

247

248

249

250

251

252

253

254

255

256

257

258

259

260

261

262

263

264

265

266

267

268

269

270

271

remagnetized by the shock. To our knowledge, this is the first time that shock experiments actually increase the original NRM of a rock. The increase of the magnetization of the microdiorite after the shock does not mean that SRM acquisition is more efficient than TRM acquisition. This is due to the increased capacity of the microdiorite to acquire a remanent magnetization after the shock (i.e. increase of $\mathrm{M}_{\mathrm{r}} / \mathrm{M}_{\mathrm{s}}$ by a factor up to five) and primarily to the fact that the original remanence was carried almost entirely by the grains with high coercivity so that the shock added a secondary low-coercivity SRM to the original highcoercivity TRM that was not much affected by the shock.

In view of the rather unstable behaviour of the NRM of the microdiorite and the schist under $\mathrm{AF}$ demagnetization and the high resistance of the NRM of the rhyolite to AF demagnetization (Fig. 10), only the basalt was suitable for a detailed study of the the ffect of shock on the remanence. For the basalt that has a simple demagnetization behaviour under alternating field and a TRM carried by grains spanning the whole coercivity spectrum, we can compare the magnetization slope (dNRM/dAF) for shocked and unshocked samples as a function of the peak alternating field (Fig. 13). Above 10-15 mT, all shocked samples located more than $15 \mathrm{~mm}$ from the impact point (peak pressure $<6 \mathrm{GPa}$ ) closely follow the curve for the unshocked basalt. Contrarily, heavily shocked samples (B5 to B14) plot below the unshocked samples between 10 and $40 \mathrm{mT}$. Above $40 \mathrm{mT}$ all curves are identical. On the interval 10-40 $\mathrm{mT}$, these heavily shocked samples have a magnetization that has the same direction as the original TRM. This means that the original TRM of samples B5 to B14 has been partly demagnetized on the 10-40 mT coercivity window. If a SRM or a TRM has been acquired on the same coercivity window during the shock, it is small enough not to be noticeable on the demagnetization plot, i.e. it is at most a few \% of the original TRM. We can quantify the shock demagnetization of the original TRM on the 10-40 mT coercivity interval by comparing the amount of NRM demagnetized between $10 \mathrm{mT}$ and $40 \mathrm{mT}$ for pre- and post-shock samples (fig. 14). Up to a distance of $14 \mathrm{~mm}$ from the impact, corresponding to a peak pressure of about $7 \mathrm{GPa}$ (sample B14), the original TRM of shocked samples has been significantly demagnetized. For sample B5 that has suffered peak pressure around $20 \mathrm{GPa}$, the original TRM has been divided by up to a factor 5. It is noteworthy that attempting a paleointensity measurement on such a shocked sample would be problematic since it is impossible to notice that part of the TRM has been demagnetized by shock. Although it is not clear how this demagnetization is dispatched along the blocking temperature spectrum, the paleointensity experiment would at best provide an underestimated value (up to a factor 5 in the case of sample B5 for instance). 
272

273

274

275

276

277

278

279

280

281

282

283

284

285

286

287

288

289

290

291

292

293

294

295

296

297

298

299

300

301

302

303

304

Generally speaking the effect of the explosive-driven shocks on the NRM of the four studied lithologies appear rather weak compared to a number of previous studies performed on isothermal remanent magnetization (IRM). Complete demagnetization of the IRM of a titano-magnetite bearing basalt shocked with a laser pulse was observed at about $2 \mathrm{GPa}$ (Gattacceca et al. 2006). Shock experiments with a gas gun on pyrrhotite-bearing samples showed a $80 \%$ demagnetization of IRM at only $0.5 \mathrm{GPa}$ (Louzada et al., in press). The large differences are attributed to the fact that NRM and IRM react differently to shock waves.

\section{Conclusion}

Experimental shocks of four rocks with different lithology and magnetic mineralogy show that, in most cases (only the hematite case is not conclusive), the intrinsic magnetic properties of the rock are permanently modified by the shock wave. A remarkable effect, not documented in previous studies, is the capacity of the shock wave to superimpose a new fabric (with a minimum susceptibility axis parallel to the direction of impact) to the original magnetic fabric of the rock. Multidomain magnetite-, pseudo-single domain titanomagnetiteand monoclinic pyrrhotite-bearing rocks show a noticeable increase of their coercivity for pressure above $10 \mathrm{GPa}$. These changes are not annealed even at high temperature $\left(580^{\circ} \mathrm{C}\right)$. They are attributed to fracturing and/or dislocations of the ferromagnetic grains. This fracturing is also responsible for the appearance of a shock-induced anisotropy of magnetic susceptibility. These results show that the magnetic properties of meteorites which are commonly shocked to pressures well above $10 \mathrm{GPa}$ (e.g. Martian meteorites, Nyquist et al., 2001) may not be representative of the magnetic properties of their parent body.

For (titano)magnetite bearing rocks, we observe both a shock demagnetization of the original TRM for magnetic grains with coercivity up to $40 \mathrm{mT}$, and a possible shock magnetization for grains with coercivity up to $10 \mathrm{mT}$. NRM appears to be much more resistant to shock than IRM (probably because they have different coercivity spectra), implying that more work is needed on the effects of shock on natural magnetization. As observed by Cisowski and Fuller (1978), the demagnetizing effects of the shock wave depend closely on the coercivity spectrum of the grains carrying the original remanence, and the shock-remagnetizing effect depend on the presence (or creation by the impact itself) of low-coercivity magnetic grains. With an impact occurring in an ambient magnetic field of similar intensity to the original magnetizing field, the post-shock magnetization may be higher or lower than the pre-shock magnetization depending on these two factors. 
305 To summarize, although an impact occurring after dynamo shutdown will indeed demagnetize

306 the crust to a variable extent, an impact occurring while the dynamo is still active may

307 demagnetize the crust almost as efficiently or conversely may lead to the situation where the

308 shocked crust has a stronger magnetization than the surrounding rocks (depending on the

309 efficiency of SRM acquisition, and on the nature of the original NRM). Therefore, it appears

310 difficult to draw conclusions about the dynamo history of a planet by studying the magnetic

311 anomalies above its impact basins, unless the anomalies provide information about the

312 magnetization of the rocks heated during the impacts (if they are preserved). The decisive clue

313 to the presence of an active dynamo at the time of impact is the presence or absence of a

314 thermoremanence carried by the volume of rocks heated above blocking temperatures during

315 the impact. Similarly, it may be difficult to determine which magnetic phase dominates the

316 crust based only on the demagnetization pattern around impact basins. 


\section{Acknowledgements}

This work was supported by the Programme National de Planétologie (INSU/CNES, France). We acknowledge very constructive comments by S. T. Stewart-Mukhopadhyay and an anonymous reviewer.

\section{References}

Auroux, E., and Deleignies, M., 2003. Sensitivity of the EOS of detonation products to the parametrization of the intermolecular potential for pure fluids in thermomechanical calculations. Proceed ings of $5^{\text {th }}$ international Symposium of high dynamic pressures, CEA eds, p. 281.

Cogné, J.P., 2003. PaleoMac: a Macin tosh ${ }^{\mathrm{TM}}$ application for treating paleomagnetic data and making plate reconstructions. Geochem. Geophys. Geosyst., 4, doi:10.1029/2001GC000227.

Cisowski, S.M., and Fuller, M., 1978. The effect of shock on the magnetism of terrestrial rocks. J. Geophys. Res., 83: 3441-3456.

Dickinson, T.L., and Wasilewski, P., 2000. Shock magnetism in fine particle iron. Meteor. Planet. Sci., 35: 65-74.

Dunlop, D.J., and Özdemir, Ö, 1997. Rock magnetism: fundamentals and frontiers. Cambridge University Press, Cambridge, 573 pp.

Gattacceca, J., Boustie, M., Weiss, B.P., Rochette, P., Lima, E., Fong, L.E., and Baudenbacher, F., 2006. Investigating impact demagnetization through laser impacts and SQUID microscopy. Geology, 34: 333-336.

Hargraves, R.B., and Perkins, W.E., 1969. Investigations of the effect of shock on natural reman ent magnetism. J. Geophys. Res. 74: 2576-2589.

Halekas, J.S., Lin, R.P., and Mitchell, D.L., 2003. Magnetic fields of lunar multi-ring impact basins. Meteor. Planet. Sci., 38: 565-578.

Hood, L., Richmond, N.C., Pierazzo, E., and Rochette, P., 2003. Distribution of crustal magnetic fields on Mars: shock effects of basin-forming impacts. Geophys. Res. Lett., 30, doi: 10.1029/2002GL016657.

Kletetschka, G., Eonnerney, J.E.P., Ness, N.F., and Acuña, M.H., 2004. Pressure effects on martian crustal magnetization near large impact basins. Meteor. Planet. Sci., 39: 18391848. 
Louzada, K., Stewart, S.T., and Weiss, B.P., 2005. The effect of shock on the magnetic properties of pyrrhotite, the Martian crust, and meteorites. Geophys. Res. Lett., in press.

Martelli, G., and Newton, G., 1977. Hypervelocity cratering and impact magnetisation of basalt. Nature, 269: 478-480.

Nyquist, L.E., Bogard, D.D, Shih, C.Y., Greshake, A., Stöffler, D., Eugster, O., 2001. Ages and geo logic histories of Martian meteorites. Space Sci. Reviews, 96: 105-164.

Pesonen, L.J., Deutsch, A., Hornemann, U., and Langenhorst, F., 1997. Magnetic properties of diabase samples shocked experimentally in the 4.5 to $35 \mathrm{GPa}$ range. $28^{\text {th }}$ Lunar and Planetary Science Meeting: 1087-1088.

Pilkington, M., and Grieve, R.A.F., 1992. The geophysical signature of terrestrial impact craters. Rev. Geophysics, 30: 161-181.

Pohl, J., Bleil, U., and Hornemann, U., 1975. Shock magnetization and demagnetization of basalt by transient stress up to $10 \mathrm{kbar}$. J. Geophysics, 41:23-41.

Rochette, P., Bertrand, H., Braun, C., and Berger, E., 1993. La province volcanique Pléistocène supérieur du Bas-Vivarais (Ardèche, France) : propagation de fentes crustales en échelons ? C. R. Acd. Sci. Paris, 316: 913-920.

Srnka, L.J., Martelli, G., Newton, G., Cisowski, S.M., Fuller, M.D., and Schaal, R.B., 1979. Magnetic field and shock effects and remanent magnetization in a hypervelocity impact experiment. Earth Planet. Sc. Lett., 42: 127-137.

Stöffler, D., Keil, K., and Scott, E.R.D., 1991. Shock metamorphism of ordinary chondrites. Geochim. Cosmochim. Acta, 55: 3845-3867.

Van Velzen, A.J., and Zijderveld, J.D.A., 1992. A method to study alterations of magnetic minerals during thermal demagnetization applied to a fine-grained marine marl (Trubi formation, Sicily). Geophys. J. Int., 110: 79-90.

Vlag, P., Vandamme, D., Rochette, P., and Spinelli, K., 1997. Paleomagnetism in the Esterel rocks: a revisit 22 years after the thesis of H. Zijderveld. Geologie en Mijnbouw, 76: 2133.

Wilkins, M.L., 1999. Computer simulation of dynamic phenomena. Springer eds, New York, 246 pp. 


\section{Figure captions}

Figure 1 - Sketch illustrating the different steps of the sampling after explosion. The wire used to saw the parallelepipeds is $220 \mu \mathrm{m}$ in diameter.

Figure 2 - Modelled pressure versus time at various depths in the rock straight below the explosion. The modelling was performed with a Johnson Wilkins Lee law for the explosive and the Radioss code for the shock wave propagation in the sample (see text).

Figure 3 - Peak pressure versus depth in the rock straight below the explosion. The pressure values are deduced from the shock wave modelling presented in Fig. 2. The solid line is computed with a density of $2300 \mathrm{~kg} \cdot \mathrm{m}^{-3}$, the dashed line is computed with a density of $3000 \mathrm{~kg} \cdot \mathrm{m}^{-3}$.

Figure 4 - Modelled peak temperature versus depth in the sample straight below the explosion, considering the amount of heat transferred to the to by the explosion of the PETN detonator. Dashed line is at $50^{\circ} \mathrm{C}$. The modelling was performed using Carte and FEMLAB codes (see text).

Figure 5 - Thermomagnetic curves for the four studied lithologies (susceptibility vs. temperature). Empty circles indicate the beginning of the heating curves. Heating = thick lines, cooling $=$ thin lines. For the basalt and the microdiorite, progressive TRM acquisition curves are also plotted (dotted line, with standard deviation when available).

Figure 6 - Representative hysteresis loops for shocked and unshocked samples of the four studied lithologies. The loops have been corrected for the paramagnetic slope.

Figure 7 - Hysteresis properties vs. depth for the shocked samples $\left(\mathrm{M}_{\mathrm{r}}\right.$ : remanent magnetization at saturation, $M_{s}$ : saturation magnetization, $B_{c r}$ : coercivity of remanence, $B_{c}$ : coercivity). Dashed line is the mean value for unshocked samples (grey band $=$ one standard deviation).

Figure 8 - Low-field specific magnetic susceptibility of impacted samples. Pre-impact mean are indicated with one standard deviation (grey bands).

Figure 9 - a-c) Degree of anisotropy of magn etic susceptibility (Pams = ratio of maximum to minimum principal susceptibility values) vs. distance to the impact. Pre-impact means are indicated (dashed line) with one standard deviation (grey bands). b-d) Lower-hemisphere equal area stereographic projection of minimum axis of magnetic susceptibility $\mathrm{K}_{3}$.

Figure 10 - Orthogonal demagnetization plots of oriented samples of the shocked rocks. Open and solid symbols represent projections of the magnetization vector on vertical and horizontal planes, respectively. Demagnetization plots for oriented unshocked samples are given for comparison. Demagnetization steps are $5,10,15, \ldots, 50,60,70,80,100,120,140$ $\mathrm{mT}$.

Figure 11 - Equal-area stereo graphic projection of the directions of magnetization $\left(0^{\circ}=\right.$ North and $90^{\circ}=$ East in Fig. 10). Open (solid) dots represent projection onto upper (lower) hemisphere. Open ellipses are the projections of the $95 \%$ confidence cones about the directions. Diamond: ambient field during the impact; $\mathrm{K}_{1}\left(\mathrm{resp} . \mathrm{K}_{3}\right)$ : maximum (resp. minimum) susceptibility principal axis, large labelled circles: low-coercivity components, small circles: high-coercivity components; large labelled star: pre-impact direction of magnetization (determined on a separate core), star: mean direction of the high-coercivity components of shocked samples.

Figure 12 - Sum of demagnetized vectors (scalar intensity) normalized by saturation magnetization vs. distance from the impact. The dotted line represents an unshocked sample.

Figure 13 - NRM slope (dNRM/dAF) as a function of alternating field for shocked basalt samples. The curve for pre-shock NRM (dashed line) is plotted for comparison. Curves are normalized to saturation magnetization (Ms) to take into account the possible variability in titanomagnetite content. Data for demagnetizing field below $10 \mathrm{mT}$ are not represented 
because the origin of the low coercivity component is not ascertained for the basalt (see text).

Figure 14 - Mean degree of shock demagnetization of the basalt on the 10-40 mT coercivity window as a function of distance to impact. This value is derived from the ratio of the NRM moment demagnetized between $10 \mathrm{mT}$ and $40 \mathrm{mT}$ before and after shock. 


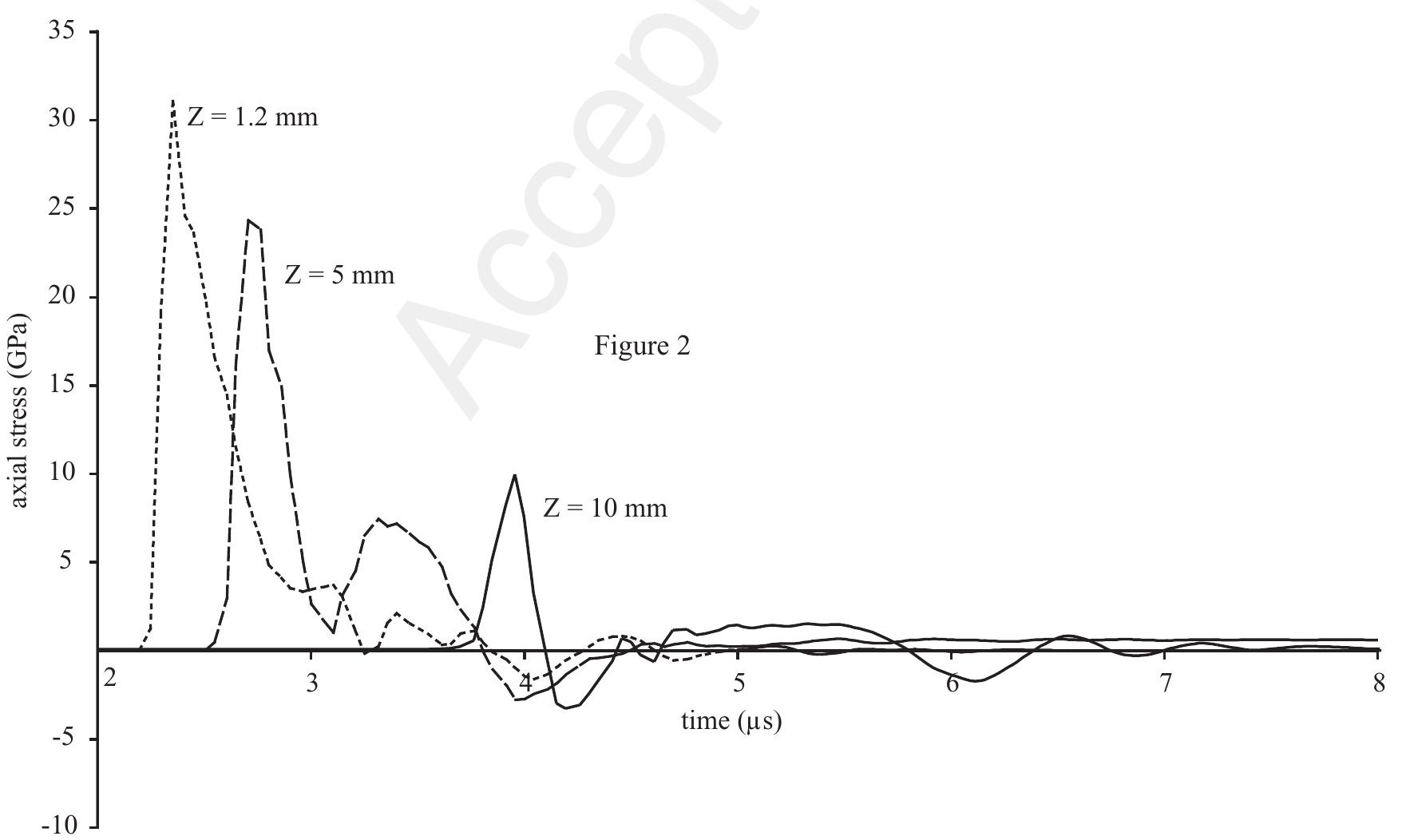




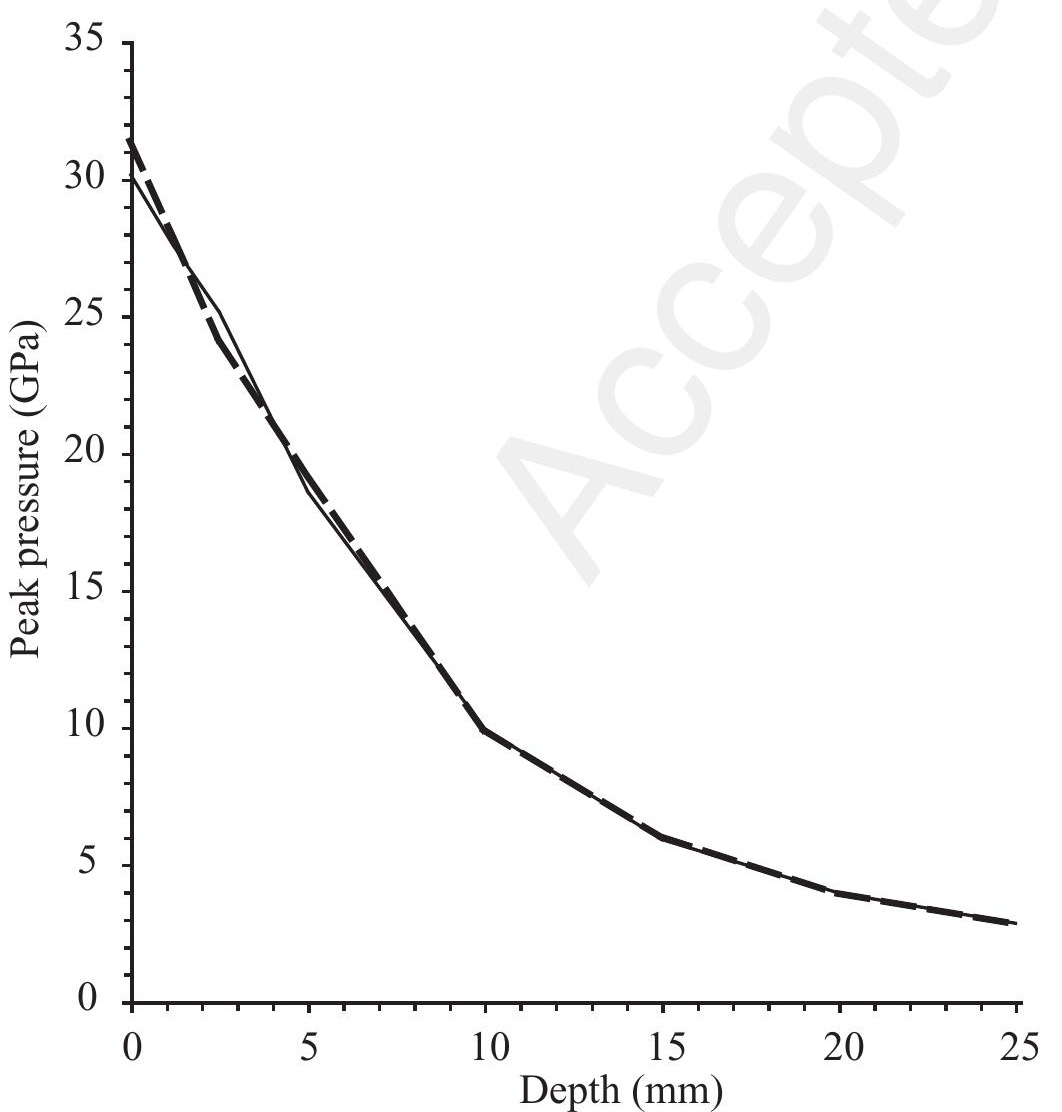

Page 18 of 30 


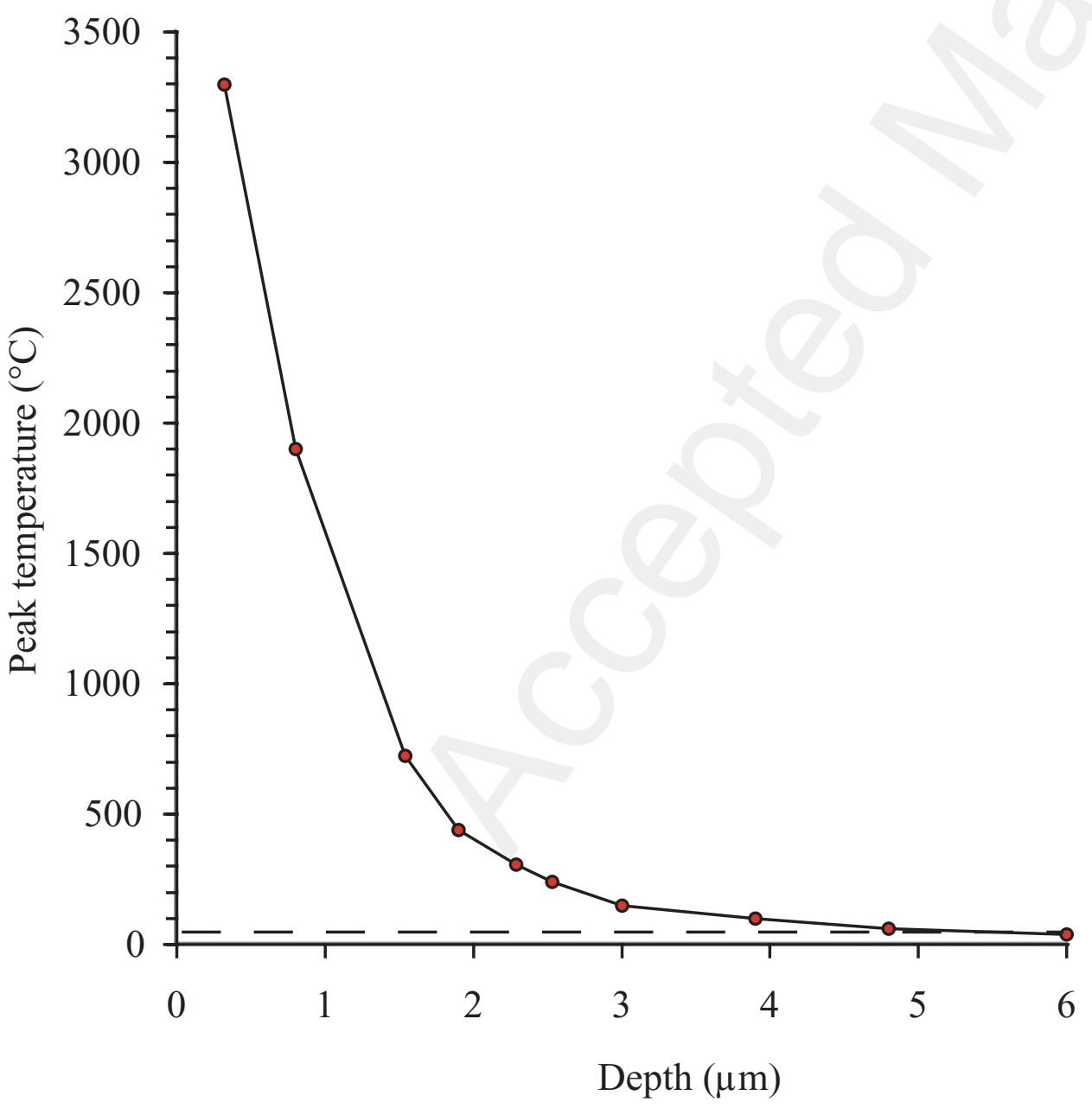

Figure 4 

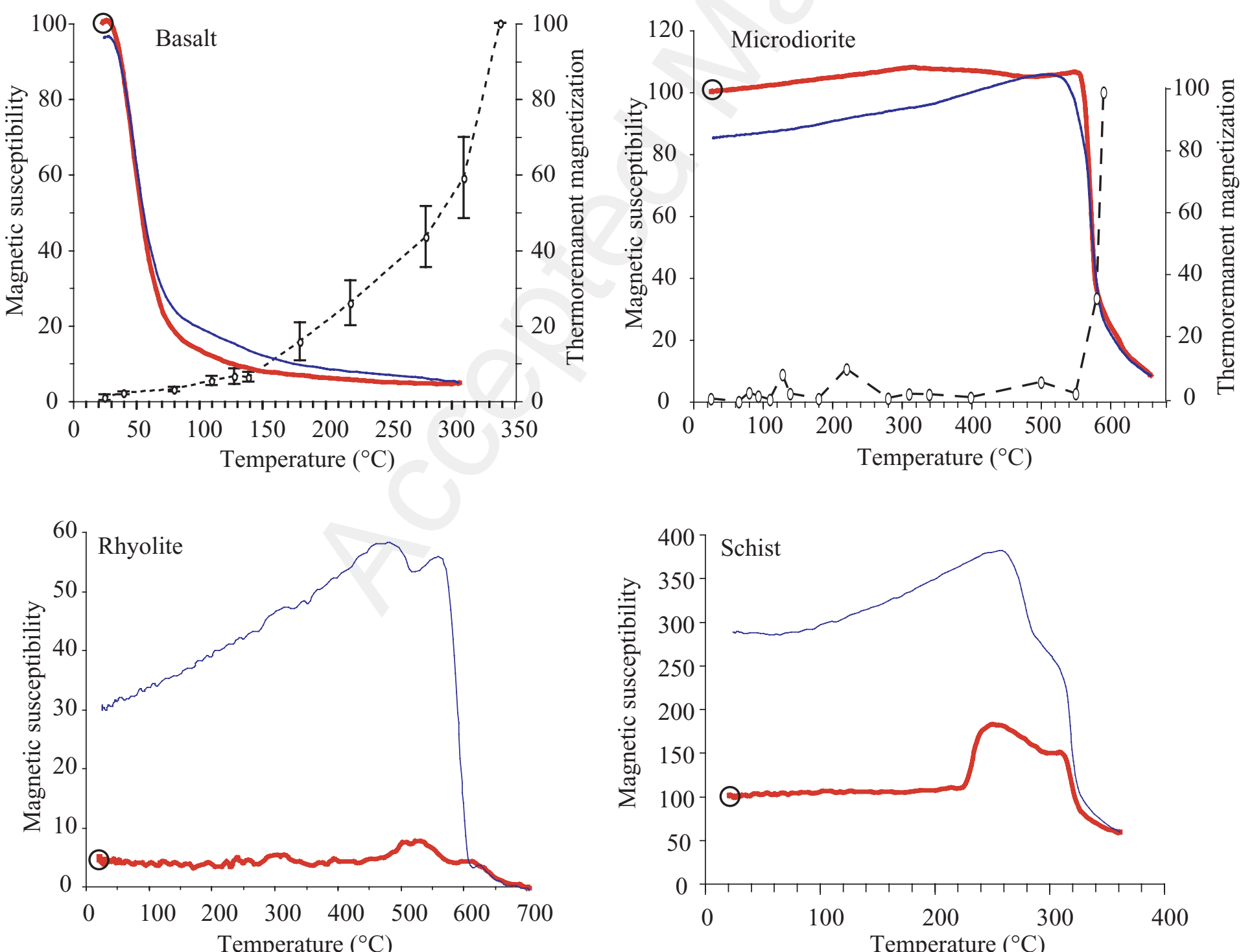

Temperature $\left({ }^{\circ} \mathrm{C}\right)$ 

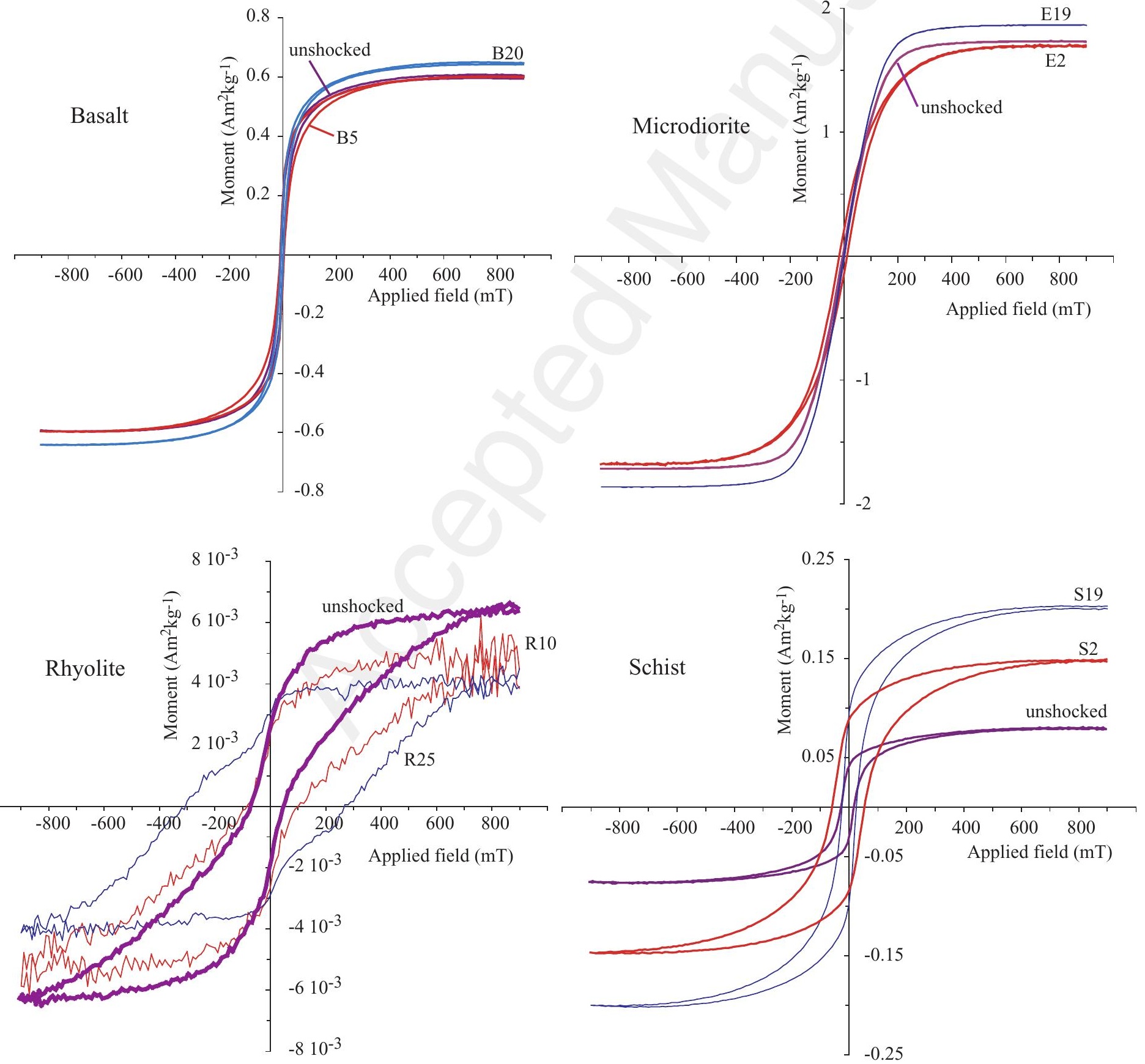

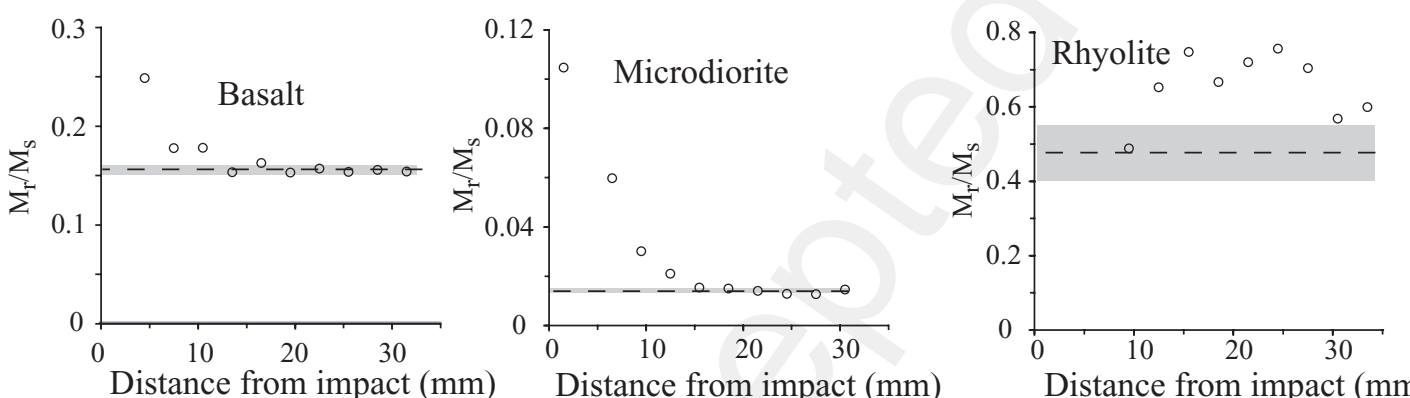

Distance from impact ( $\mathrm{mm})$
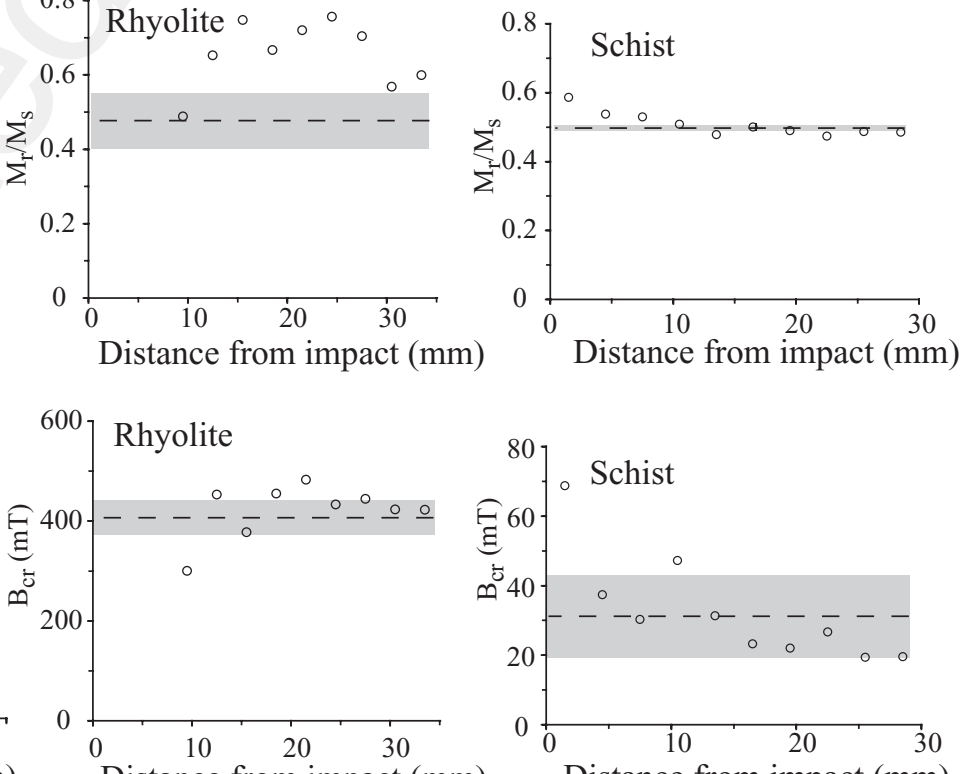

Distance from impact (mm)
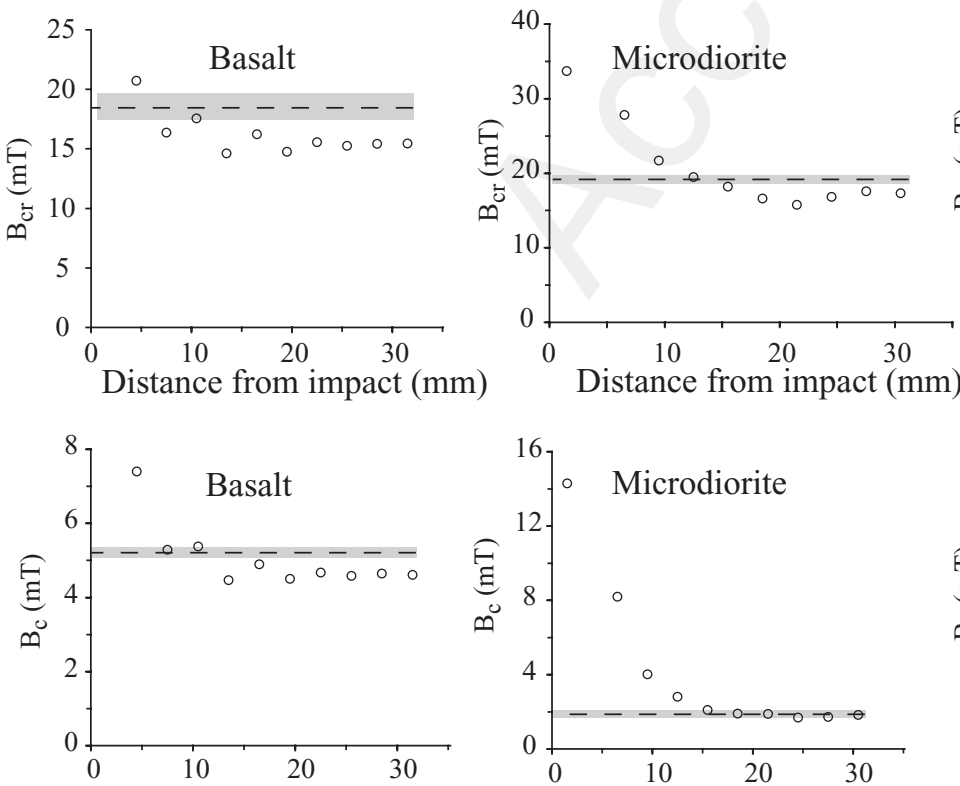

Distance from impact (mm)
Distance from impact (mm)

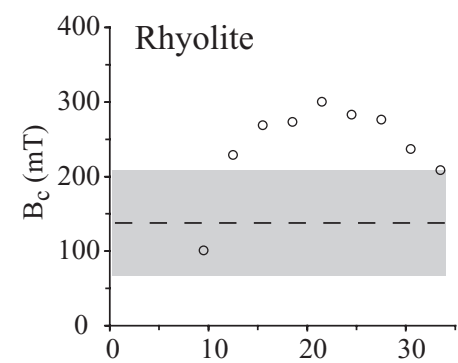

Distance from impact (mm)

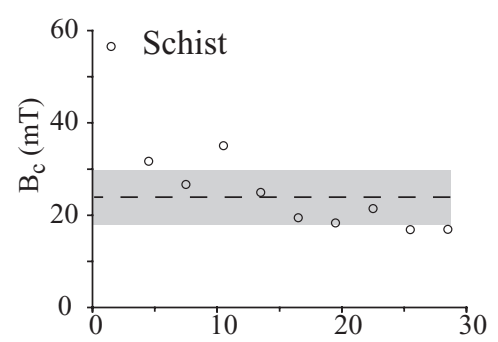

Distance from impact $(\mathrm{mm})$ Page 22 of 30 

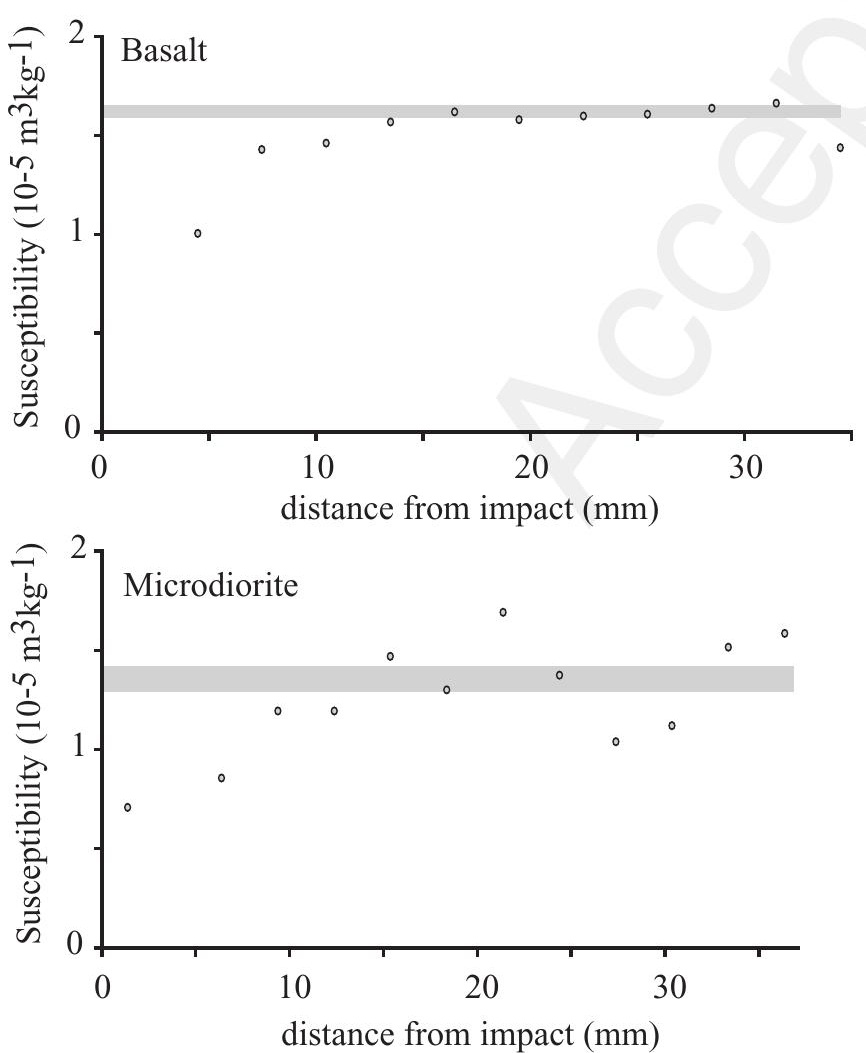

Page 23 of 30 


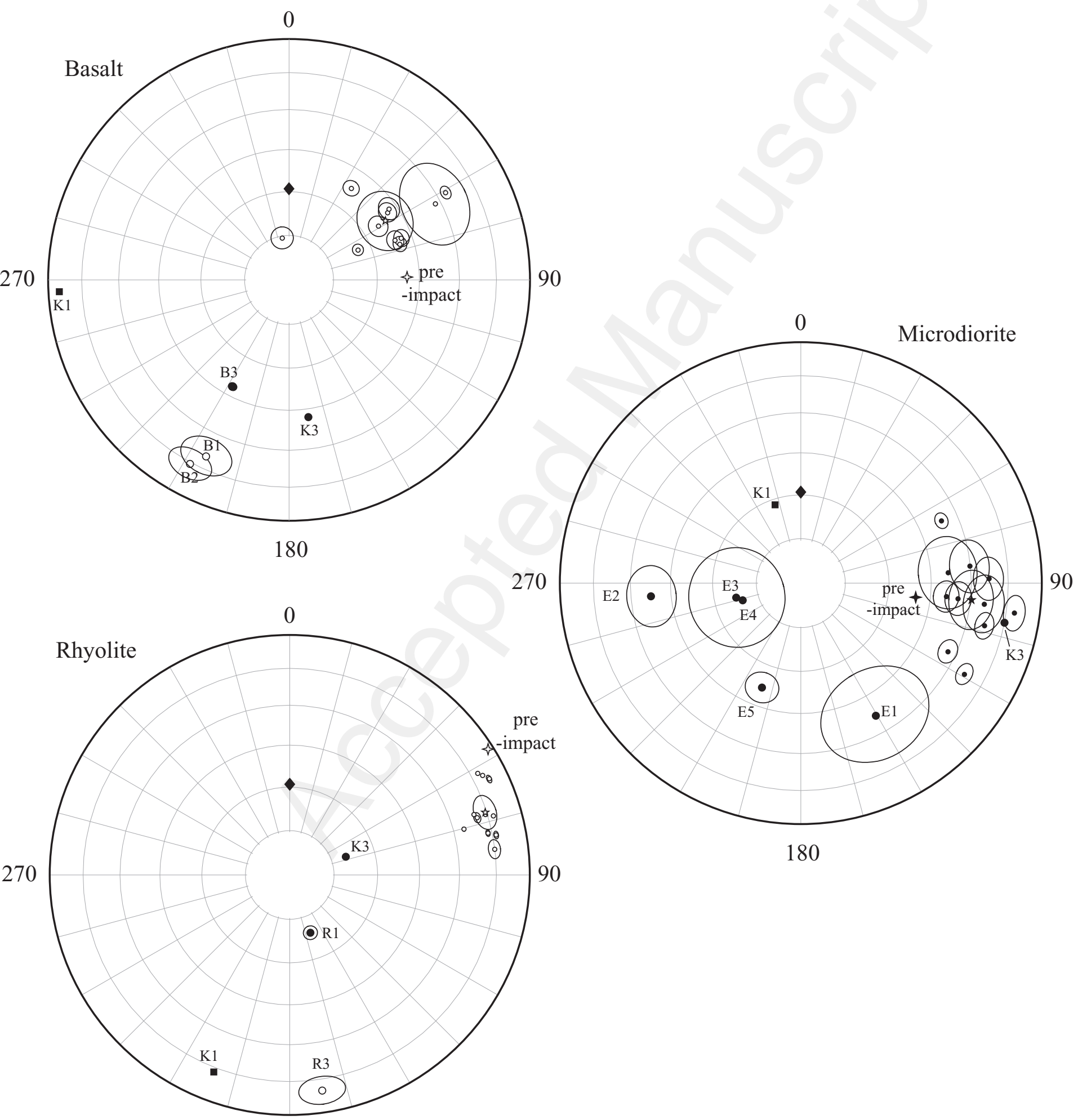




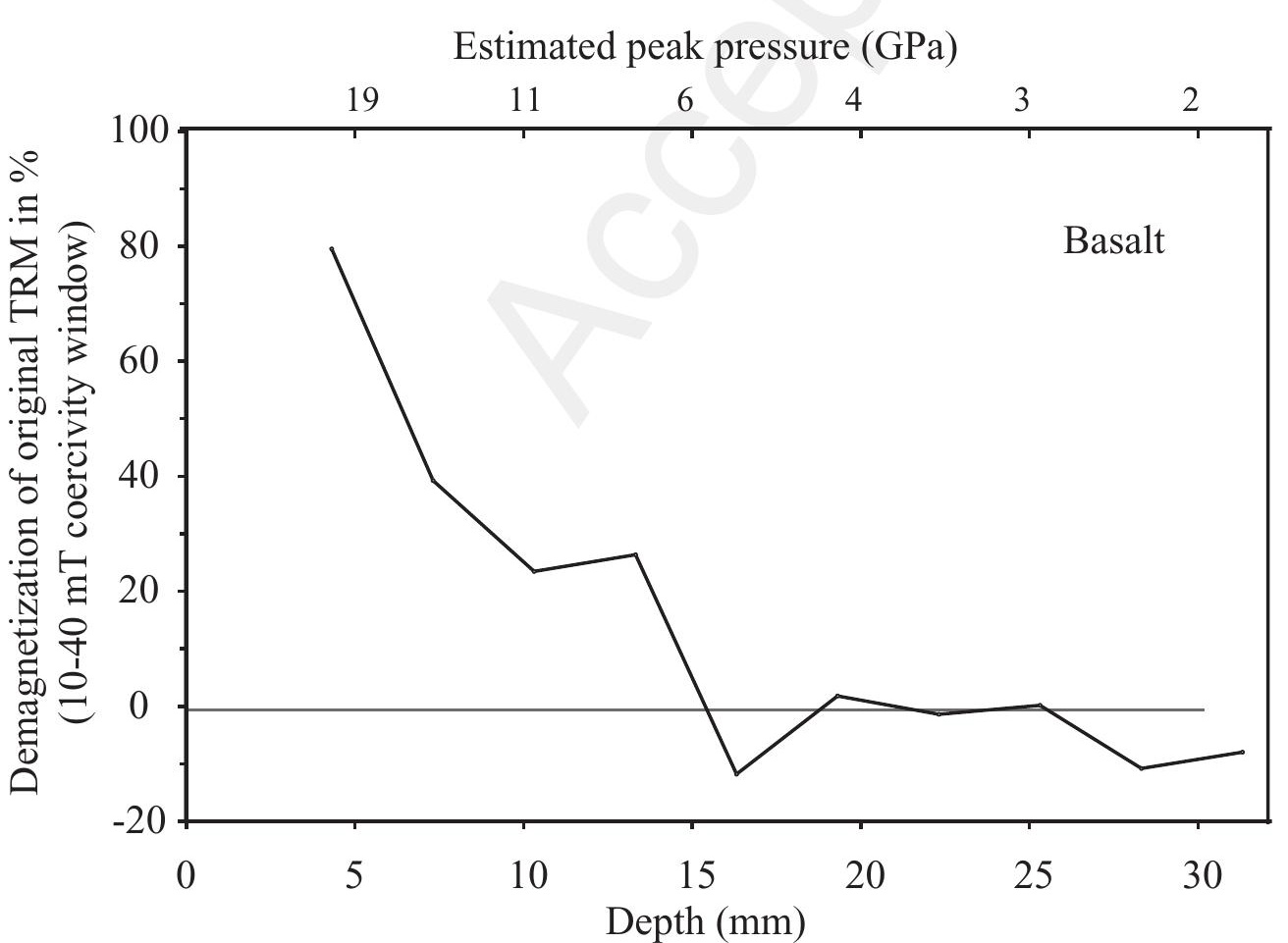

Page 29 of 30 
Tables

Table 1 - Physical parameters used in the shock and thermal simulations.

\begin{tabular}{|c|c|c|c|c|c|c|c|c|}
\hline \multirow[t]{2}{*}{$\begin{array}{l}\text { Explosive } \\
\text { (PETN) }\end{array}$} & $\begin{array}{c}\rho_{\mathrm{o}} \\
\left(\mathrm{g} . \mathrm{cm}^{-3}\right)\end{array}$ & $\begin{array}{c}\mathrm{D} \\
\left(\mathrm{m} \cdot \mathrm{s}^{-1}\right)\end{array}$ & $\begin{array}{c}\mathrm{P}_{\mathrm{CJ}} \\
(\mathrm{GPa})\end{array}$ & $\begin{array}{c}\mathrm{A} \\
(\mathrm{GPa})\end{array}$ & $\begin{array}{c}\mathrm{B} \\
(\mathrm{GPa})\end{array}$ & $\mathrm{R}_{1}$ & $\mathrm{R}_{2}$ & $\omega$ \\
\hline & 1.77 & 8300 & 33.35 & 617 & 16.93 & 4.4 & 1.2 & 0.25 \\
\hline \multirow[t]{2}{*}{ Basalt } & $\begin{array}{c}\rho_{\mathrm{o}} \\
\left(\mathrm{g} . \mathrm{cm}^{-3}\right)\end{array}$ & $\begin{array}{c}\mathrm{C}_{\mathrm{o}} \\
\left(\mathrm{m} \cdot \mathrm{s}^{-1}\right)\end{array}$ & $\mathrm{S}$ & $\Gamma$ & $\begin{array}{c}\mathrm{Y}_{\mathrm{o}} \\
(\mathrm{GPa})\end{array}$ & $\begin{array}{c}\mathrm{k} \\
\left(\mathrm{W} \cdot \mathrm{m}^{-1} \cdot \mathrm{K}^{-1}\right)\end{array}$ & $\begin{array}{c}\mathrm{C} \\
\left(\mathrm{J} \cdot \mathrm{kg} \cdot \mathrm{K}^{-1}\right)\end{array}$ & \\
\hline & 2.88 & 4800 & 1.34 & 2 & 0.3 & 1.99 & 1000 & \\
\hline
\end{tabular}

$\rho_{\mathrm{o}}$ : density; $\mathrm{D}$ : shock speed; $\mathrm{P}_{\mathrm{CJ}}$ : Chapman-Jouguet pressure; $\mathrm{A}, \mathrm{B}, \mathrm{R}_{1}, \mathrm{R}_{2}$ : JWL parameters associated to the JWL equation mentioned in the text (Wilkins, 1999); $\omega$ : Grüneisen coefficient; $\mathrm{C}_{\mathrm{o}}$ : sound speed; $\mathrm{S}$ : empirical parameter; $\Gamma$ : Grüneisen coefficient; $\mathrm{Y}_{\mathrm{o}}$ : yield stress; $\mathrm{k}$ : thermal conductivity; $\mathrm{C}$ : heat capacity.

Table 2 - Magnetic properties of materials before shock

\begin{tabular}{lcccc} 
& Basalt & Microdiorite & Rhyolite & Schist \\
\hline Hysteresis & $\mathrm{n}=10$ & $\mathrm{n}=12$ & $\mathrm{n}=10$ & $\mathrm{n}=10$ \\
$\mathrm{Mr}\left(\mathrm{Am}^{2} \mathrm{~kg}^{-1}\right)$ & $9.78 \pm 0.6710^{-2}$ & $2.38 \pm 0.2010^{-2}$ & $2.31 \pm 0.2210^{-3}$ & $4.48 \pm 2.9010^{-2}$ \\
$\mathrm{Ms}\left(\mathrm{Am}^{2} \mathrm{~kg}^{-1}\right)$ & $6.22 \pm 0.4610^{-1}$ & $1.28 \pm 0.1410^{-1}$ & $4.91 \pm 0.7210^{-3}$ & $9.14 \pm 6.0210^{-2}$ \\
$\mathrm{Mr} / \mathrm{Ms}$ & $1.57 \pm 0.0310^{-1}$ & $1.39 \pm 0.0710^{-2}$ & $4.77 \pm 0.7310^{-1}$ & $4.99 \pm 0.2810^{-1}$ \\
$\mathrm{Bc}(\mathrm{mT})$ & $5.19 \pm 0.16$ & $1.86 \pm 0.08$ & $137 \pm 69$ & $23.8 \pm 5.9$ \\
$\mathrm{Bcr}(\mathrm{mT})$ & $18.4 \pm 1.1$ & $19.1 \pm 0.7$ & $406 \pm 35$ & $31.3 \pm 11.7$ \\
$\mathrm{Bcr} / \mathrm{Bc}$ & $3.54 \pm 0.14$ & $10.3 \pm 0.4$ & $3.56 \pm 1.47$ & $1.29 \pm 0.12$ \\
Susceptibility & $\mathrm{n}=22$ & $\mathrm{n}=28$ & $\mathrm{n}=9$ & $\mathrm{n}=7^{*}$ \\
Susceptibility $\left(\mathrm{m}^{3} \mathrm{~kg}^{-1}\right)$ & $1.61 \pm 0.0310^{-5}$ & $1.35 \pm 0.0710^{-5}$ & $3.31 \pm 0.5810^{-8}$ & $3.19 \pm 0.2010^{-7}$ \\
AMS & $\mathrm{n}=8$ & $\mathrm{n}=8$ & $\mathrm{n}$ & \\
An is otropy degree & $1.029 \pm 0.009$ & $1.040 \pm 0.008$ & $\mathrm{n}=19$ & $\mathrm{n}=7 *$ \\
Magnetization & $\mathrm{n}=14$ & $\mathrm{n}=13$ & & \\
NRM (Am $\left.{ }^{2} \mathrm{~kg}^{-1}\right)$ & $1.70 \pm 0.2210^{-3}$ & $1.71 \pm 0.1210^{-4}$ & $4.19 \pm 0.4410^{-5}$ & $6.60 \pm 2.8410^{-5}$ \\
\hline For each magn & &
\end{tabular}

For each magnetic property, the number of measured samples (n) is indicated.

* For susceptibility and magnetization of the schist, only samples with mass $>1 \mathrm{~g}$ have been taken into account due to small-scale heterogeneities in pyrrhotite concentration. 